\title{
A review of the antibacterial activity of ozenoxacin
}

\author{
Rafael Canton $* 1,2$, Luc Chouinard ${ }^{3}$ \& Cristina Tarragó ${ }^{4}$ \\ ${ }^{1}$ Servicio de Microbiología, Hospital Universitario Ramón y Cajal \& Instituto Ramón y Cajal de Investigación Sanitaria (IRYCIS), \\ Madrid, Spain \\ ${ }^{2}$ Red Española de Investigación en Patología Infecciosa (REIPI), Madrid, Spain \\ ${ }^{3}$ Charles River Laboratories Montreal ULC., Senneville, Canada \\ ${ }^{4}$ Spherium Biomed, Barcelona, Spain \\ *Author for correspondence: rafael.canton@salud.madrid.org
}

First draft submitted: 2 March 2018; Accepted for publication: 16 March 2018; Published online: 10 May 2018

\section{Keywords: Gram-positive bacteria $\bullet$ impetigo $\bullet$ ozenoxacin $\bullet$ quinolones}

Impetigo is a highly contagious common bacterial skin infection, which is particularly prevalent in children aged $2-5$ years. It is classified clinically based on the type of skin lesion, as nonbullous and bullous. Nonbullous impetigo (impetigo contagiosa), which occurs in around 70\% of cases, is caused by Staphylococcus aureus or Streptococcus pyogenes infection. Bullous impetigo is caused by toxin-producing $S$. aureus. Impetigo can occur either as a primary infection or secondary to another condition, such as scabies or atopic dermatitis (atopic eczema) following disruption of the skin barrier $[1,2]$.

A recent systematic review of the global epidemiology of impetigo reported a median prevalence of $11.2 \%$ (interquartile range [IQR]: 4.2-19.4\%; 89 studies) in the general population, with the prevalence in children (12.3\%; IQR: 4.2-19.4\%; 82 studies) being around 2.5-fold higher than that in adults (4.9\%; IQR: 3.1-9.6\%; 11 studies) [3]. In some remote isolated communities, the prevalence of impetigo approaches $50 \%[3,4]$.

Systematic reviews and meta-analyses of interventions for impetigo showed that two topically administered antibacterial agents, mupirocin and fusidic acid, are as effective or more effective than oral antibacterial agents [5,6]. However, fusidic acid-resistant $S$. aureus strains in nonbullous impetigo and secondarily infected atopic dermatitis [7], and mupirocin-resistant $S$. aureus strains in pediatric recurrent skin and soft tissue infections [8,9] have been described, which limit the efficacy of these topical antibacterials. Alternative topical antibiotics for impetigo are retapamulin [2,6] and ozenoxacin, a nonfluorinated quinolone [10]. A recent Phase III clinical trial showed that topical ozenoxacin was effective and safe in the treatment of impetigo [11].

This supplement provides in vitro and in vivo data for the antibacterial activity of ozenoxacin against Grampositive isolates, which illustrate several features of the compound. A comparative in vitro study of ozenoxacin with a panel of antibacterial agents shows that ozenoxacin has high antibacterial activity at low concentrations against Gram-positive isolates obtained from skin and soft tissue infections [12]. The therapeutic efficacy of ozenoxacin is examined in rodent models of $S$. aureus dermal infection [13], and the potential chrondrotoxicity of ozenoxacin, which is a known adverse effect in fluorinated quinolone antibacterials, is evaluated in juvenile rats and dogs [14].

\section{Financial \& competing interests disclosure}

The studies included in the supplement were supported by Ferrer Internacional, Barcelona, Spain. C Tarragó was an employee of Ferrer Internacional at the time the studies were performed. The authors have no other relevant affiliations or financial involvements with any organization or entity with a financial interest in or financial conflict with the subject matter or materials discussed in the manuscript apart from those disclosed.

Writing assistance was provided by Content Ed Net (Madrid, Spain) with funding provided by Ferrer International SA (Barcelona, Spain). 


\section{References}

1. Sladden MJ, Johnston GA. Common skin infections in children. BMJ 329, 95-99 (2004).

2. Hartman-Adams H, Banvard C, Juckett G. Impetigo: diagnosis and treatment. Am. Fam. Physician 90, 229-235 (2014).

3. Bowen AC, Mahé A, Hay RJ et al. The global epidemiology of impetigo: a systematic review of the population prevalence of impetigo and pyoderma. PLoS ONE 10, e0136789 (2015).

4. Romani L, Steer AC, Whitfeld MJ, Kaldor JM. Prevalence of scabies and impetigo worldwide: a systematic review. Lancet Infect. Dis. 15, 960-967 (2015).

5. George A, Rubin G. A systematic review and meta-analysis of treatments for impetigo. Br. J. Gen. Pract. 53(491), 480-487 (2003).

6. Koning S, van der Sande R, Verhagen AP et al. Interventions for impetigo. Cochrane Database Syst. Rev. 1, CD003261 (2012).

7. Alsterholm M, Flytström I, Bergbrant IM, Faergemann J. Fusidic acid-resistant Staphylococcus aureus in impetigo contagiosa and secondarily infected atopic dermatitis. Acta Derm. Venereol. 90, 52-57 (2010).

8. McNeil JC, Hulten KG, Kaplan SL, Mason EO. Mupirocin resistance in Staphylococcus aureus causing recurrent skin and soft tissue infections in children. Antimicrob. Agents Chemother. 55(5), 2431-2433 (2011).

9. Simor AE, Stuart TL, Louie L et al. Mupirocin-resistant, methicillin-resistant Staphylococcus aureus strains in Canadian hospitals. Antimicrob. Agents Chemother. 51(11), 3880-3886 (2007).

10. Yamakawa T, Mitsuyama J, Hayashi K. In vitro and in vivo antibacterial activity of T-3912, a novel non-fluorinated topical quinolone. J. Antimicrob. Chemother. 49(3), 455-465 (2002).

11. Gropper S, Albareda N, Chelius K et al. Ozenoxacin $1 \%$ cream in the treatment of impetigo: a multicenter, randomized, placebo- and retapamulin-controlled clinical trial. Future Microbiol. 9(9), 1013-1023 (2014).

12. Canton R, Morrissey I, Vila J et al. Comparative in vitro antibacterial activity of ozenoxacin against Gram-positive clinical isolates recovered from skin and soft tissue infections. Future Microbiol. 13(6s), 3-19 (2018).

13. Tarragó C, Pérez Esquirol L, Arañó A et al. Therapeutic efficacy of ozenoxacin in animal models of dermal infection with Staphylococcus aureus. Future Microbiol. 13(6s), 21-30 (2018).

14. González Borroto JI, Awori MS, Chouinard L et al. Studies on articular and general toxicity of orally administered ozenoxacin in juvenile rats and dogs. Future Microbiol. 13(6s), 31-40 (2018). 